[Agr. Biol. Chem., Vol. 32, No. 3, p. 394 395, 1968]

\title{
A New Antifungal Substance Produced by Myrothecium
}

Sir:

Recently many strains of mold were isolated from soils by the authors and screening tests of antibiotics productivity were performed on those strains by them. As a results they have discovered a new antibiotic substance in fermentation broth of a fungus isolated from a soil sample collected in Bangkok of Thailand.

Temporarily this antibiotic was designated as A-2 material and the producing mold as strain No. 310-1. A-2 was later found to be a new member of antibiotics, the Verrucarin and Roridin group reported by $\mathrm{Ch}$. Tamm et al., i.e. Verrucarin A, B, C, D, E, F, G, $\mathrm{H}, \mathrm{J}$ and Roridin $\mathrm{A}, \mathrm{B}, \mathrm{C}, \mathrm{D}, \mathrm{E}$ which were the products of Myrothecium verrucaria and $M$. roridium. In this communication the authors wish to deal with the production, isolation, physicochemical and biological properties and chemical structure of A-2.

When strain No. 310-1 was cultivated in a medium containing glucose $1 \%$, peptone $0.10^{\circ}$ and yeast extract $0.1 \%$ at $30^{\circ} \mathrm{C}$ for $96 \mathrm{hr}$ by jarfermentor, seven antibiotic compounds were accumulated in the culture fluid. The fluid was centrifugated at $10,000 \mathrm{rpm}$ to remove the mycelium. After the supernatant, 50 liters was concentrated in vacuo to 5 liters, 10 liters of acetone was added to it in order to precipitate the viscous material and the supernatant was again concentrated in vacuo to 5 liters. The concentrate was extracted four times with ether at $\mathrm{pH} 2.0$. The combined extracts were then evaporated in vacuo to yield an yellowish oily material, which was dissolved in a small amount of benzene and adsorbed onto a silica gel column. It was developed with 1 liter of benzene, and then with 1 liter

1) E. Härri, W. Loeffer, H. P. Sigg, H. Stähelin, Ch. Stoll, Ch. Tamm, Helw. Chim. Acta, 45, 839(1962); B. Bohner, E. Fetz, E. Harri, H. P. Sigg, Ch. Stoll and Ch. Tamm ibid., 48, 1079 (1965). of benzene-ethyl acetate $(95: 5)$. The active fraction obtained by the latter development was concentrated in vacuo to give yellowish oily Verrucarin B, which was crystallized with ether. A-2 was found in mother liquor of Verrucarin B and recovered from the solution by repeated column chromatography. Final mother solution was treated by subsequent thin layer chromatography of Kiesel gel G with benzene-methanol $(6: 1)$. The purified fraction of A-2 was eluted with ether. The ether solution was concentrated, and crystals thus yielded were recrystallized from benzene-methanol to white prisms $(1.2 \mathrm{mg})$.

A-2 had $\mathrm{mp} 147 \sim 148^{\circ} \mathrm{C}$ and $[\alpha]_{\mathrm{B}}^{05}-14(c=$ 1.01, methanol). Anal. Found: $\mathrm{C}, 65.09 ; \mathrm{H}$, 7.45; O, 27.46. Calcd. for $\mathrm{C}_{19} \mathrm{H}_{26} \mathrm{O}_{6}: \mathrm{C}, 65.12$; $\mathrm{H}, 7.48 ; \mathrm{O}, 27.40 \%$ : MW 350.40. The mass spectral data of A-2 showed its MW to be 350 which precisely coincided with the theoretical value. The infrared spectrum was demonstrated in Fig. 1. The ultraviolet absorption spectrum had only end absorption. A-2 was easily soluble in most organic solvents such as methanol, acetone, chloroform, ether and benzene, and sparingly soluble in hexane and petroleum ether.

A-2 exhibited specific antifungal activity against Trychophyton asteroides (M.I.C. $0.1 \mu \mathrm{g} / \mathrm{ml}$ ) and T. interdigitale (M.I.C. $10 \mu \mathrm{g} / \mathrm{ml}$ ). It was less active against yeast and other kinds of fungi such as Aspergillus, Penicillium, Fusarium, Piricularia and Glomerella and inactive against

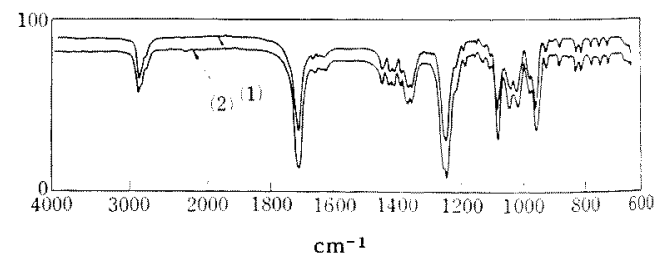

FIG. 1. Infrared Spectra of $A-2(1)$ and 4,1j. Diacetylverrucarol (2) in $\mathrm{KBr}$. 
bacteria including Mycobacterium.

According to the above-mentioned data and NMR spectrum, A-2 was assumed to be an acetylated Verrucarol skeleton shown in Fig. 2. In order to confirm this the comparison of A-2 and the authentic specimen was carried out. The specimen was synthesized by acetylation of Verrucarol which was made by alkali-hydrolysis of Verrucarin $B$. The mixture melting point test of A-2 and the specimen showed no depression. Moreover, infrared spectra of both were in perfect agreement with each other (Fig. 1).

Obviously, therefore, compound A-2 was defined to have the structure of 4,15-diace-

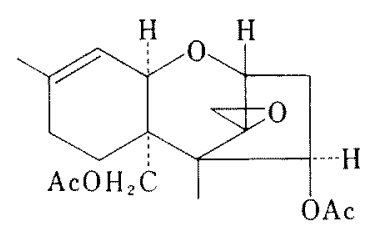

FIG. 2. The Structure of 4,15-Diacetylverrucarol. tylverrucarol (Fig. 2), being a hitherto unknown antibiotic occuring in nature. The mold No. 310-1 was also identified taxonomically to belong to genus Myrothecium, but the details will be published elsewhere.

The authors express their gratitude to Dr. K. Wada, Nagoya University, for his kind advice. They also dedicate their thanks to researchers in Laboratory of Fermentation Chemistry, Nagoya University for their help and assistance rendered to this study. They were much indebted to Dr. N. Sasaki, Department of Chemistry, Nagoya University for taking mass spectra and to Kowa Pharmaceutical Co. for elementary analysis.

\section{Masao ÔKuchI \\ Masao ITOH \\ Yasuyuki KaneKo Shinji Dor}

Laboratory of Fermentation Chemistry, Department of Agricultural Chemistry, Nagoya University, Nagoya

Received February 1, 1968 